\title{
PRÁCTICAS PERFORMÁTICAS FEMINISTAS CUESTIONANDO LAS NOCIONES DE GUSTO SOCIAL
}

\author{
FEMINIST ART PERFORMANCE \\ QUESTIONING THE HEGEMONIC NOTION OF SOCIAL JUDGMENT \\ NATALIA CAROD / nataliacarod26@gmail.com \\ Instituto de Historia del Arte Argentino y Americano. Facultad de Artes. \\ Universidad Nacional de La Plata. Argentina
}

Recibido 13/12/2019 | Aceptado 7/4/2020

\section{RESUMEN}

El presente artículo indaga en prácticas performáticas utilizadas como medios principales de denuncia y de visibilización de la violencia de género en los últimos años por artistas y por activistas latinoamericanas. En contextos de lucha feminista la acción performática agencia discursos que han sido expulsados y enviados a la periferia del campo social dominante. Se considera que dichos discursos producen una disputa por el capital simbólico de lo que es entendido por política y, por ende, de lo que es entendido por estética, cuestionando la noción hegemónica de gusto social asociada al imperativo heteropatriarcal. Para ello, se analizan tres manifestaciones performáticas acontecidas en los últimos cinco años en Chile y en la Argentina, tomando como referencia la primera movilización Ni Una Menos en la Argentina en el año 2015.

\section{PALABRAS CLAVE}

Prácticas performáticas; gusto social; feminismo; política; disidencias

\section{ABSTRACT}

This research article looks to explore the performance practices used to bring gender violence to the forefront of social consciousness by Latin American female artists and activists. These performances have been inspired by the modern feminist and their struggle to reverse how these issues have been pushed aside and out of the mainstream consciousness. These issues are controversial and the intention to keep them out of the social zeitgeist stems from fear of how they could encourage observers to question the current definition of politics and public perceptions of aesthetics; questioning the hegemonic notion of social judgment associated with the patriarchal imperative. For that purpose, three demonstrative art performances will be analysed; including those in both Chile and Argentina. The most notable of which was the «Ni Una Menos» -Not one less-demonstration in Argentina in 2015.

\section{KEYWORDS}

Performance discipline; social zeitgeist; feminism; politics; controversies 


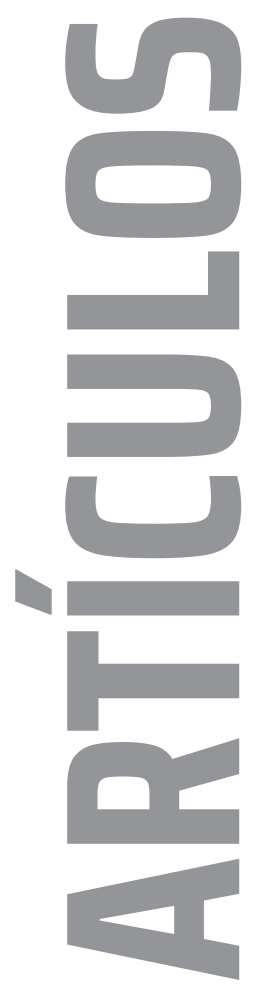

En los últimos años las acciones performáticas han cobrado mayor visibilidad como medio de protesta dentro del campo social y del campo político, estableciendo con mayor fuerza las relaciones de poder que existen entre campo cultural, campo de poder y campo social. La lucha por el capital simbólico, en este caso manifestada a través de la lucha contra la violencia de género en sus diferentes variantes, posibilita que los discursos poéticos actúen como una red que expone el entramado que han tejido las políticas de carácter patriarcal y machista, visibilizando a su vez las políticas heteronormativas. ¿Por qué en los últimos años los discursos poéticos de carácter performático se han convertido en la herramienta principal de lucha feminista? ¿Es porque la acción performática como discurso político manifiesta a través de los cuerpos la posibilidad de disidencia? ¿Por qué el discurso poético acepta y visibiliza un cuerpo otro, y los discursos sociales - provenientes del campo dominante- invisibilizan dichos cuerpos otros? ¿Se debe, acaso, a una cuestión de gusto social establecida por la sociedad heteropatriarcal?

Desde los años setenta el arte de performance ha sido el medio principal utilizado por las artistas visuales feministas para denunciar y para visibilizar temáticas de género. Las temáticas abordadas por militantes, activistas y artistas feministas se centraban en el papel que debía cumplir la mujer según las imposiciones de la sociedad patriarcal; entre las denuncias cuestionaban el papel de ama de casa y la maternidad. Es desde aquel entonces que el cuerpo se vuelve un lugar de enunciación para las artistas feministas, ya que en él es donde se inscriben las relaciones de poder; sus cuerpos alejados de los confines del hogar y de las tareas asignadas e impuestas por la sociedad patriarcal se vuelven un espacio de subversiones (Castro Sánchez, 2018).

En la actualidad, las movilizaciones sociales impulsadas por los movimientos feministas posibilitan la producción de acciones performáticas que comparten las mismas temáticas de la movilización: denunciar y visibilizar la problemática de violencia de género.

En la ciudad de La Plata se encuentra el grupo Las Amandas, una colectiva de actrices que interviene el espacio público, desde la primera movilización Ni Una Menos, con el objetivo de interpelar a las/los transeúntes y visibilizar temáticas en torno a la problemática de violencia de género. El 8 de marzo de 2020 durante el Paro Nacional y Plurinacional de Mujeres, Lesbianas, Travestis, Trans, Bisexuales y No binaries realizaron una acción performática tanto en Plaza San Martín como en Plaza Moreno que consistió en describir en una palabra las diferentes violencias que sufren las mujeres y disidencias. Las artistas recitaban una palabra cada una, al mismo tiempo que dejaban impreso en el suelo con un esténcil la frase "No miente, no miento»; al finalizar dejaban flores sobre estas impresiones, en alusión a las flores que se dejan en las tumbas de víctimas de femicidio [Figura 1]. 

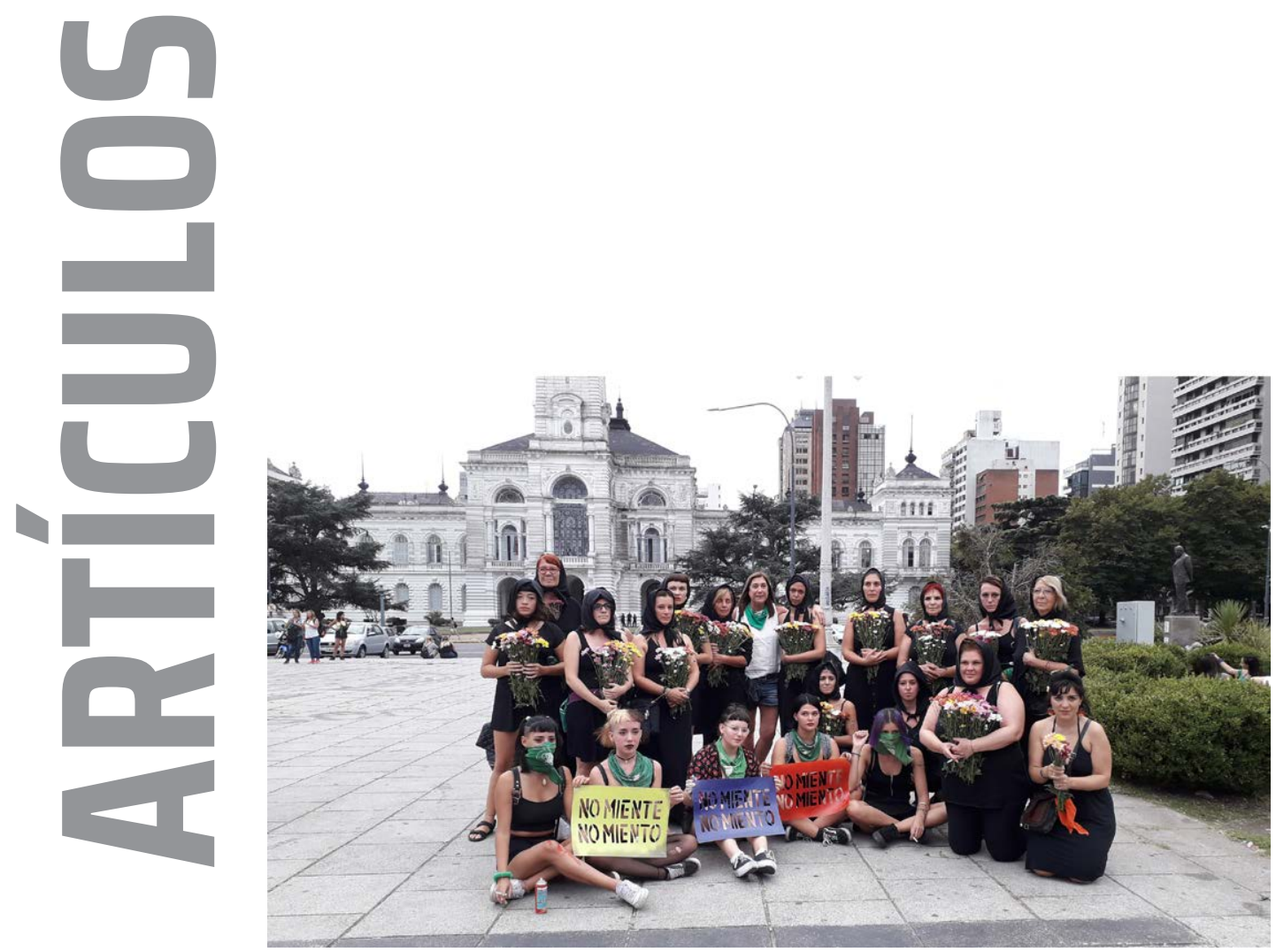

Figura 1. No miente, no miento (2020), acción performática de Las Amandas. Archivo fotográfico personal

En la Ciudad Autónoma de Buenos Aires, en el año 2017 en vísperas de la movilización Ni Una Menos, el grupo Fuerza Artística de Choque Comunicativo (FAAC) realizó una intervención performática frente a los tres poderes del Estado: Casa Rosada, Tribunales y Congreso Nacional. Bajo el lema "Femicidio es Genocidio», 120 mujeres se desnudaron y apilaron sus cuerpos aludiendo a la cantidad de femicidios en el año, que para ese entonces eran 133. Al finalizar, acompañadas de una orquesta de músicas, recitaron fragmentos de tres poemas: «Nombremos a todas» (2011), de Paula Heredia; "Otro sí digo» (2009), de Gabriela Robledo; «India» (2011), de Patricia Karina Vergara Sánchez [Figura 2].

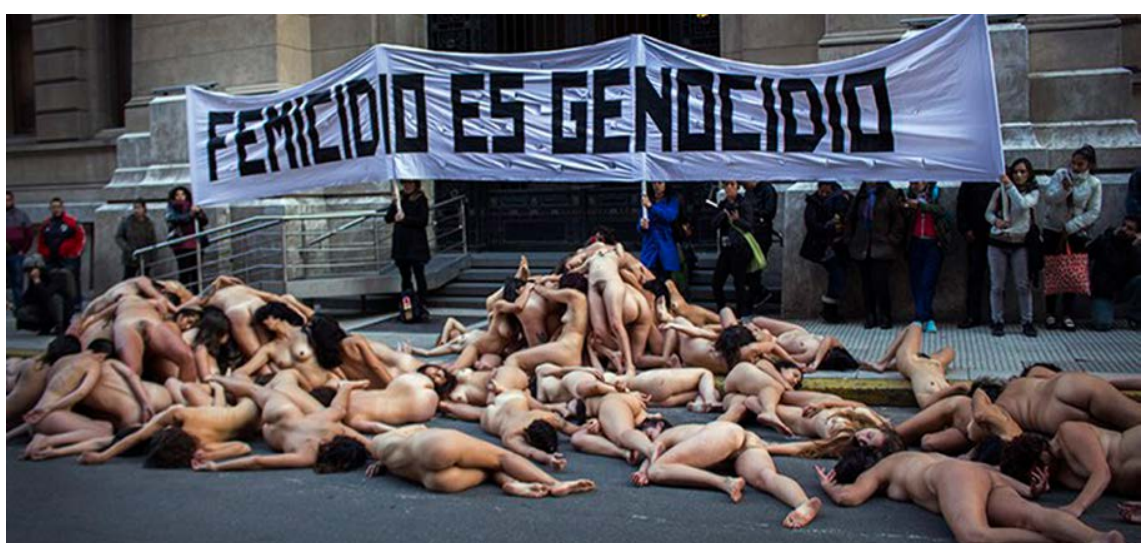

Figura 2. Femicidio es genocidio (2017), acción performática del grupo FACC. Archivo fotográfico de Sofía Genovese 


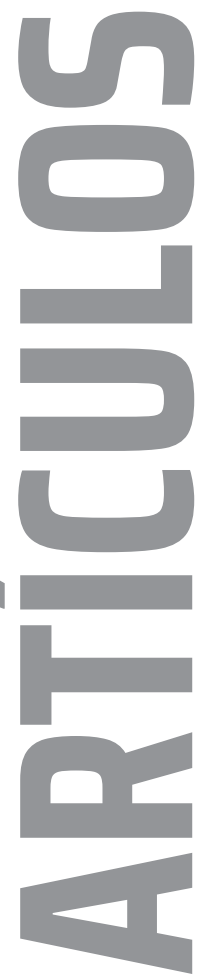

Otro ejemplo es la acción performática que se realizó en Chile bajo la consigna «Un violador en tu camino». En noviembre de 2019, luego de los sucesos de protestay de represión en Chile, la población se movilizó para exigir al Estado responsabilidad por los femicidios y ataques sexuales. El grupo de artistas escénicas Las Tesis convocó a miles de mujeres chilenas a participar en una performance colectiva; con los ojos vendados repitieron la frase «Y la culpa no era mía ni dónde estaba ni cómo vestía. El violador eras tú. El violador eres tú». La acción performática se viralizó por las redes sociales y en varios puntos geográficos del mundo artistas y activistas la realizaron, incluyendo la Argentina [Figura 3].

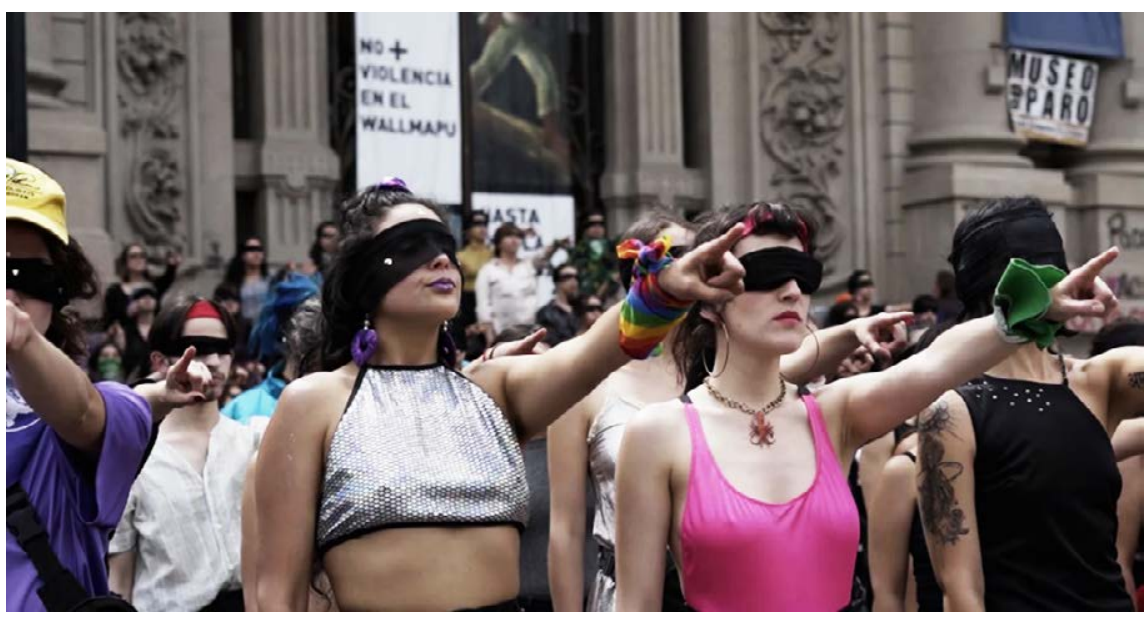

Figura 3. Un violador en tu camino (2019), acción performática de Las Tesis. Archivo fotográfico de Elisa Torres

Las manifestaciones ciudadanas, al ser eventos sociales y políticos, masivos y públicos, permiten a los actores y a las actrices que allí interactúan —activistas, militantes, artistas, población en general- trabajar de manera colectiva y colaborativa para lograr el objetivo mismo de la protesta: construir proyectos sociales democráticos (Castro Sánchez, 2018). En ellas se produce un vínculo dialéctico entre las apuestas políticas y el arte, al incorporar expresiones artísticas como estrategias de lucha (Longoni, 2010). Los movimientos feministas, y las movilizaciones que estos impulsan, se han convertido en un campo propicio para la producción de manifestaciones escénicas feministas. Dichas manifestaciones escénicas cuestionan las nociones de gusto social establecidas en la sociedad heteropatriarcal al utilizar al cuerpo de las mujeres como un espacio de enunciación de discursos que visibilizan las desigualdades entre los géneros y las violencias ejercidas hacia ellas. 


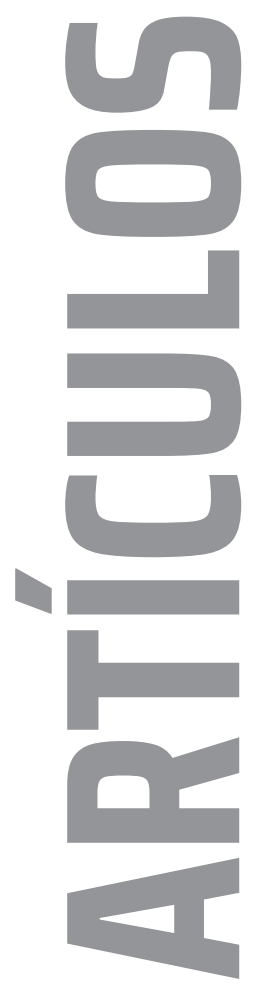

La primera movilización Ni Una Menos (2015) ha sido un punto de partida para pensar las diferentes formas de protesta como acciones políticas y poéticas. Es en este entorno cuando las protestas de género pasan a formar parte de las efemérides culturales, políticas y sociales. Si bien en periodos anteriores al 2015 existieron protestas que problematizaron y visibilizaron temáticas relacionadas a la violencia de género, este trabajo apunta a destacar aquellas que se han producido luego de la fecha señalada, ya que es cuando la colectiva se internacionaliza. Por otro lado, al formar parte del entramado social y político, Ni Una Menos ha logrado unir en su lucha al campo cultural, al campo social y al campo político para manifestarse en contra del campo de poder, este último visible en las políticas patriarcales que rigen a las sociedades contemporáneas. Es por esto que en el presente trabajo se indaga en las prácticas performáticas como medio principal de denuncia y visibilización de la violencia de género utilizado en los últimos años por artistas/ activistas latinoamericanas; en relación con ello se analiza también cómo estas prácticas performáticas permiten cuestionar las nociones de gusto social.

\section{ESCENARIOS DE LUCHA FEMINISTA Y PRÁCTICAS PERFORMÁTICAS}

El incremento de los movimientos feministas ha impulsado y posibilitado la producción de movilizaciones sociales y políticas en la última década. Estos espacios albergan discursos políticos que pretenden problematizar la violencia de género y visibilizar los derechos de las mujeres y disidencias. Ahora bien, ¿qué alcances tienen estos espacios de lucha dentro del campo de poder o del campo cultural?, ¿cuáles son los límites que imponen estos nuevos escenarios de lucha dentro del campo social? Partir de ciertos cuestionamientos es necesario para analizar cuáles serían las poéticas/políticas que implementan las manifestaciones feministas en contextos de lucha. Es también necesario comprender estos movimientos poéticos/políticos dentro de las tensiones que se producen en el campo social en relación con el campo de poder. Muchas veces dichas tensiones se ven reflejadas en el campo cultural cuando la lucha por el capital simbólico se hace evidente a la hora de establecer discursos artísticos de carácter político.

Estos nuevos escenarios de lucha feminista exceden el límite de los confines institucionales y ponen en crisis al sistema heteropatriarcal. ${ }^{1}$ En el seno de estos escenarios surgen prácticas artísticas de carácter performático que redefinen la función de la política. ¿Cuáles son los límites del ejercicio de la política en la lucha feminista? ¿Hasta qué punto la política se basa en representación de los intereses del Estado? ¿Puede esta remodelarlos en pos de incluir a las disidencias

1 Omar Calabrese (1999) propone dos categorías, la de exceso y la de límite, para analizar el efecto de ciertos movimientos sociales en el sistema dominante. El autor sostiene que en algunos casos el sistema expande sus fronteras para integrar el exceso y de esta manera desviar el objetivo del mismo; pero, cuando no logra hacerlo, estos excesos trabajan desde la periferia provocando el rechazo por parte del sistema. 


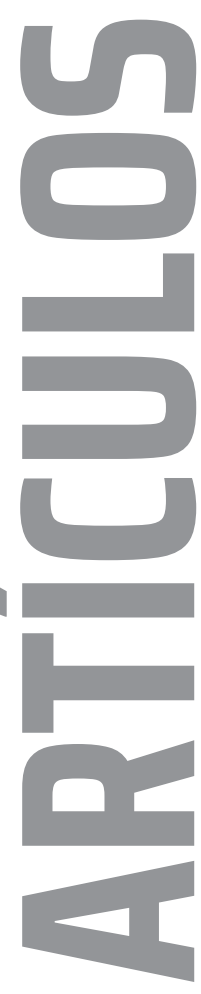

y otredades en ellos? La política es sacada de los confines de los partidos políticos y la institucionalidad formal por los movimientos feministas, para ser recreada con el fin de dar visibilidad a aquellas supuestas minorías que el poder hegemónico ha excluido todo este tiempo. ${ }^{2}$ En ese sentido, Ana María Castro Sánchez (2018) afirma:

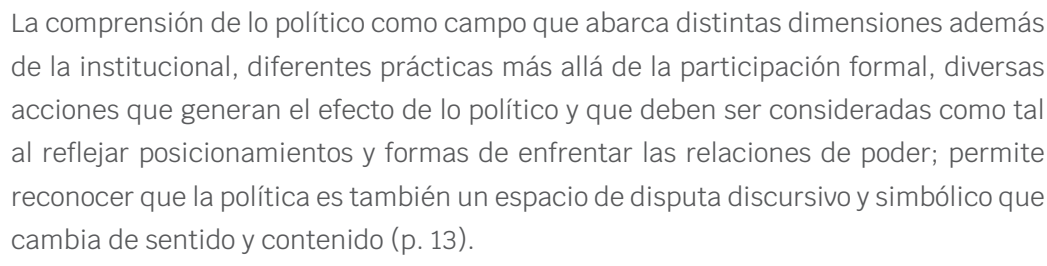

En la lucha por el capital simbólico de lo que es entendido por política, los movimientos trabajan de manera horizontal con artistas y activistas con el fin de visibilizar las diversas temáticas que allí se ponen en cuestionamiento. Se producen prácticas políticas llevadas a cabo por ciudadanos «extrañando el discurso y escenificando imaginarios y deseos colectivos en los espacios públicos» (Diéguez, 2014, s. p.), y producciones artísticas realizadas por artistas que se proponen como acciones políticas (Diéguez, 2014).

Esto permite visualizar las relaciones - y tensiones - entre arte y política en los contextos de lucha. Es dentro de estas tensiones donde el gusto social se ve interpelado, ya que no solo se manifiesta la lucha política, sino que también se manifiesta indirectamente la lucha estética, al producirse en estos escenarios acciones performáticas que funcionan como herramientas discursivas y dispositivos poéticos que agencian políticas acerca de lo que el campo dominante considera sobre la otredad.

Las acciones performáticas tanto del grupo Las Tesis en Chile como de los grupos FACC y Las Amandas en la Argentina dan cuenta de estas tensiones al politizar espacios considerados neutrales y apolíticos, espacios donde hay una supuesta naturalidad de las situaciones, como si las relaciones de poder no influyeran en ellos. Estos espacios tienen que ver con las concepciones que se tienen en torno a las corporalidades. Michel Foucault (1999) analiza las nuevas tecnologías de poder que operan sobre los sujetos, controlando a cada una/o de manera individual; ya no se trata de una prohibición sino de una desviación con respecto a la

2 Castro Sánchez (2018) afirma que la política entendida como una práctica de participación convencional de la democracia representativa, donde el que la ejerce y controla es el Estado y sus instituciones, dejando a los ciudadanos el ejercicio de esta solo en momentos o procesos democráticos como es el voto; es reconfigurada para reconocer las diversas expresiones de la misma y la diversidad de protagonistas que la ejercen y la llevan a cabo. Por tanto, la noción de política se extiende para abarcar esferas diferentes a la institucional, politizando temas, problemas, circunstancias, etcétera. 


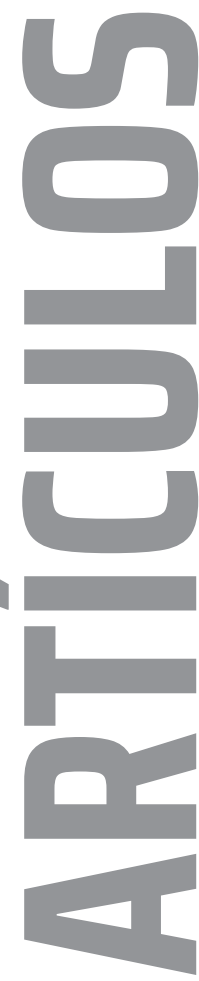

normatividad. Es en el control de los cuerpos individuales de cada sujeto donde se ven reflejadas las relaciones de poder que imparte el campo de poder dominante. Por medio de propuestas performáticas las artistas/activistas visibilizan el control ejercido sobre los cuerpos de las mujeres y disidencias; estos cuerpos otros son los que aparecen abandonados, despojados, utilizados, invalidados en la sociedad heteropatriarcal. Las propuestas performáticas analizadas tienen como objetivo visibilizar las principales formas de violencia hacia las mujeres, niñas, lesbianas, travestis, y trans: el acoso callejero, el abuso y la violación sexual, el femicidio y la desaparición forzada. A la vez, pretenden denunciar la justicia patriarcal, mediante la crítica al poder ejecutivo y judicial, tanto de la Argentina como de Chile, por la falta de respuesta y por la impunidad ante los abusos cometidos, señalando a aquellos como cómplices. La crítica es hacia aquellas relaciones de poder que hacen que algunas corporalidades sean consideradas menos válidas que otras, legitimando discursos heteronormativos. Dicha legitimación se produce mediante la práctica reguladora del sexo. Judith Butler (2002) analiza cómo las normas reguladoras del sexo trabajan de manera performativa para imponer y materializar la diferencia sexual, en pos de consolidar el imperativo heterosexual. ${ }^{3}$ Esto trae como consecuencia la performatividad del género, donde la heterosexualidad se presenta como el ideal de lo que es definido como normalidad. El cuerpo es el lugar donde se materializa esta construcción social del sexo, la cual se comprende como natural, de esta manera se vuelve imposible evidenciar que no se trata de una condición natural sino de una construcción social impuesta por el campo del poder. Es en este proceso donde una/o asume un sexo, naturalizando la opción binaria de la sexualidad, por esa identificación sexuada que exige el imperativo heterosexual, donde se excluyen y repudian a la vez otras identidades, colocándolas en el plano de la desidentidad (Butler, 2002).

¿Cómo los discursos poéticos-políticos enunciados por las artistas feministas posibilitan la visibilización de las otredades o, en palabras de Butler, de las desidentidades? ¿Por qué son los discursos poéticos de carácter performático las herramientas privilegiadas para denunciar dichas desigualdades? Diana Taylor en la «Introducción» de Estudios avanzados de performance (2011) relata cómo en Latinoamérica el surgimiento del arte de la performance se da en un período violento: marcado por golpes de Estado, desapariciones forzadas y masacres. Es por ello que la práctica de la performance tiene resonancias locales; «en momentos de dictadura los militares pueden controlar los medios, las editoriales, los guiones, todo menos los cuerpos de ciudadanos que se expresan perfectamente con gestos mínimos» (Taylor, 2011, p. 11). De esta manera, un acto espontáneo que

3 Judith Butler (2002) define a esta como «ese poder reiterativo del discurso para producir los fenómenos que regula e impone» (p. 19); de esta manera la performatividad puede ser vista como una práctica reguladora de normas que rigen nuestra conducta; la heteronorma, la maternidad y la monogamia son ejemplo de ello. 


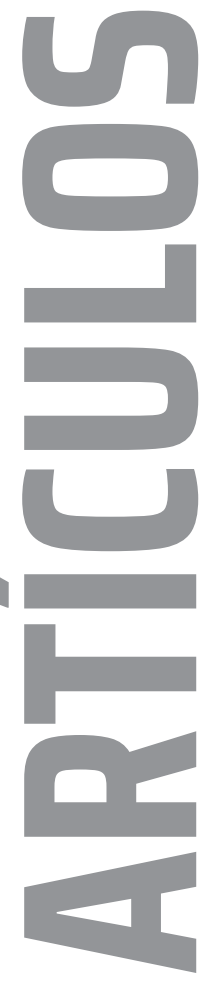

irrumpe en la cotidianeidad, como una manifestación social, puede ser analizado como performance y ser comprendido como un acto de resistencia frente a la censura (Taylor, 2011). Desviarse de la norma, de la performatividad entendida como práctica regulatoria, posibilita, por un lado, nuevas formas de hacer política, al enunciar discursos políticos comprometidos con la transformación social; $y$, por el otro, permite cuestionar el gusto estético, al valerse de prácticas artísticas como estrategias de lucha.

Un ejemplo de ello es la acción performática Femicidio es Genocidio que llevó a cabo el grupo FACC en la Ciudad Autónoma de Buenos Aires días antes de la movilización Ni Una Menos. La misma consistió en denunciar los femicidios ocurridos hasta el momento, contabilizados desde el inicio del año 2017; para ello las artistas exhibieron 120 cuerpos sobre la calle. Una de las características de esta performance, que le valió la mayoría de las críticas, es que las artistas estaban desnudas. Una mujer desnuda es aceptada en la televisión, en revistas, en películas, en posters, en publicidades, en espacios controlados por el sistema heteropatriarcal; pero ahora, si el cuerpo desnudo es utilizado por las mismas mujeres, dueñas de ellos, para visibilizar una problemática que las oprime, es entonces rechazado. De esta manera, un cuerpo desnudo expuesto en los límites de los confines de lo institucional se vuelve un campo de batalla donde se enuncian discursos políticos que la misma sociedad dominante invisibiliza.

Otro ejemplo de cómo las artistas a través de acciones performáticas brindan discursos que atentan contra el campo del poder es la acción performática Un violador en tu camino, que aconteció en Chile en el año 2019. El objetivo de esta propuesta es denunciar tanto a aquellos que ejercen la violencia como a quienes la respaldan. En esta ocasión el énfasis no está puesto en la víctima, sino en el victimario. Ya no se trata de mencionar a las víctimas de femicidio y de desaparición forzada, como lo hacen las artistas argentinas, sino de señalar con un dedo a quienes son cómplices y, por ende, responsables de sus muertes: el Estado y la justicia patriarcal. Se trata de un arte de escrache, tal como hizo el grupo H.I.J.O.S. en la Argentina cuando señalaban las casas de los militares que, luego de haber sido responsables de la desaparición, violación de derechos, asesinatos y femicidios de 30000 personas durante la dictadura militar, tenían una vida normal, en sus hogares.

Por tanto, dentro de una sociedad donde imperan los discursos heteropatriarcales, donde las tecnologías del poder operan mediante la regulación de los cuerpos, controlando la conducta de los sujetos; un acto performático, donde el cuerpo es utilizado como herramienta de visibilización de dicho control y opresión, puede transformarse en un acto de resistencia. El cuerpo entonces modelado, controlado y significado por la sociedad heteropatriarcal se convierte en una zona de conflicto donde las artistas y activistas pueden enunciar discursos emancipadores. Javier Fuentes Feo (2010) afirma: 


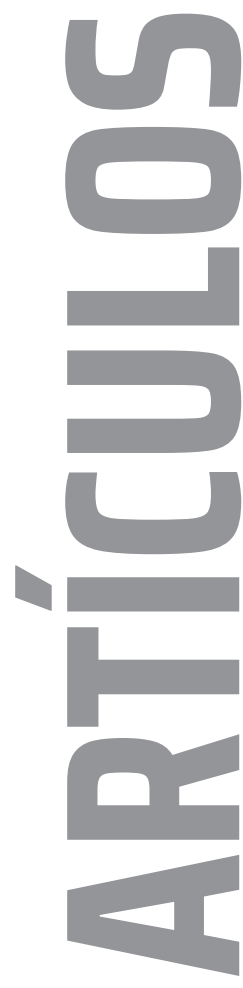

Un cuerpo educado, militarizado, consumido, medicado, (des)politizado, erotizado y espectacularizado; un cuerpo también siempre, como no, bombardeado y torturado... una y otra vez. Un cuerpo capaz de dar testimonio y de mostrar en un solo siglo, que de ser algo no es, bajo ningún concepto, uniformidad, sino en todo caso multiplicidades corporales en potencia y en resistencia; en permanente transformación (p. 13).

Teniendo en cuenta que las movilizaciones políticas a lo largo de la historia han producido cambios sociales en donde el arte ha ocupado un lugar dentro de dichos escenarios, se hace posible pensar que poética y política, en el contexto de las protestas feministas en Latinoamérica, son una herramienta de visibilización de los discursos sociales disidentes. La acción performática, en contextos de lucha feminista, agencia discursos que han sido expulsados a la periferia del campo social dominante; en consecuencia, estos discursos producen una disputa por el capital simbólico de lo que es entendido por política y, por ende, lo que es entendido por estética, cuestionando la noción hegemónica de gusto social asociada al imperativo heteropatriarcal.

\section{ATACAR LO ESTÉTICO PARA DESLEGITIMAR LO POLÍTICO}

El campo de poder, sobre todo aquel que legitima las manifestaciones artísticas y políticas que circulan por el entramado social, agencia manifestaciones poéticas y artísticas ya legitimadas para deslegitimar las acciones performáticas realizadas en contextos de lucha feminista. Es en este contexto de tensiones entre los campos donde, en el proceso de legitimación y deslegitimación de poéticas performáticas, se filtran los discursos sobre el sentido social del gusto (Bourdieu, 2010). Entonces, ¿dichas construcciones sobre el gusto social atentarían en contra del objetivo político de las acciones performáticas? ¿Estética, política y gusto social serían conceptos incompatibles en los contextos de lucha política? ¿Qué es lo que sucede cuando estos cuerpos desnudos son sacados del entramado del discurso heteropatriarcal y son utilizados como discursos políticos de la lucha feminista?

Los cuerpos de la acción performática Femicidio es genocidio (2017) arrojados frente a los edificios que representan los tres poderes del Estado, repudiados por un sector del público y también por los medios hegemónicos de comunicación que responden a las lógicas del sistema patriarcal; ponen en jaque la noción de gusto social por lo que los sectores en desacuerdo atacan lo estético para desvalorizar la lucha política que se está llevando a cabo. Pero, este ataque demuestra lo que Jacques Rancière (2010) denomina como lo intolerante de la imagen; las imágenes, en específico las imágenes del arte político, a través de ciertas estrategias plásticas de composición, evocan un acto de representación donde se pone en juego lo visible y lo invisible. Estas imágenes de mujeres pidiendo a gritos auxilio, desnudas, pasando frío se vuelven intolerantes, no por ser demasiado reales, sino por el diálogo que se genera entre ellas y las/los espectadores. En dicho diálogo 


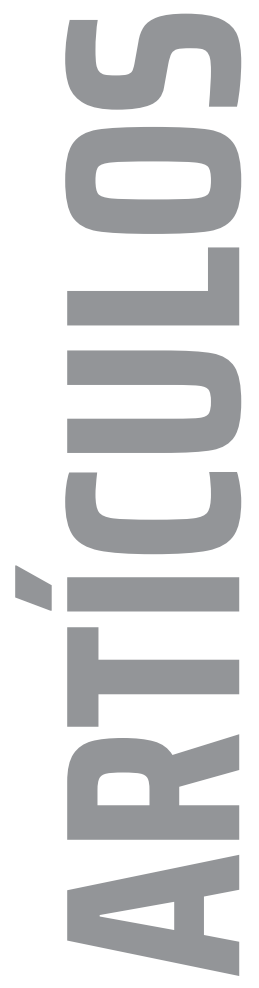

no solo se visibiliza la problemática de violencia de género, sino que también se exige el reconocimiento de la complicidad con el sistema patriarcal y violento que produce que esas imágenes se hagan cuerpo.

Otro ejemplo que permite reflexionar y cuestionar sobre el sentido social del gusto es la acción performática que aconteció durante el Paro Nacional y Plurinacional de Mujeres el 8 de marzo de 2020 en La Plata. En ella Las Amandas hacen hincapié en las diferentes violencias, humillaciones y discriminaciones que sufren las mujeres, niñas, lesbianas, travestis y trans. Lo lúdico en esta propuesta está puesto en la utilería: las flores. Dichos objetos poseen un doble significado: por un lado, se entregan comúnmente a las personas a modo de obsequio; por el otro, se otorgan como ofrendas para honrar la memoria de los y las difuntas. Podría considerarse que este doble -y conflictivo- significado hace alusión a la dialéctica que se produce entre los regalos ideales que la sociedad heteropatriarcal impulsa durante el festejo del Día de la Mujer, asociados al imaginario heteropatriarcal femenino: flores, productos estéticos - zapatos, cosméticos, ropa-, objetos de cocina, entre otros; y el regalo ideal exigido por los movimientos feministas, que se expresa en frases como «ni zapatos ni flores, solo paren de matarnos». También en esta oportunidad se desarticula la noción de gusto social presentándola como contradictoria.

Si se centra la atención en la lucha social feminista podría entonces también comprenderse que dicho discurso es deslegitimado porque las agentes que lo llevan a cabo provienen del sector oprimido por la sociedad patriarcal: las mujeres y la comunidad LGTBQIA+. El repudio y la invisibilización se generan por dos cuestiones: por un lado, porque en estos escenarios las relaciones de poder que impone la sociedad patriarcal se invierten y son las disidencias las que llevan a cabo e imparten la política —entendiendo a esta acción como aquella que politiza espacios considerados neutrales, como se menciona en el apartado anterior-. Castro Sánchez (2018) define:

\footnotetext{
Los movimientos feministas son reconocidos por las transformaciones que han suscitado en la concepción de la política y el ejercicio que se hacía de la misma; pensando la política de manera más amplia al reconocer que su concepción y práctica tradicional era limitante para quienes no ostentaban el poder, particularmente las mujeres a quienes les era negado por su condición y posición de género, así como a las personas racializadas y subalternizadas (pp. 14-15).
}

Por el otro, porque el feminismo no solo tiene un lado positivo, donde hay empoderamiento y sororidad, sino también un lado negativo donde quienes toman conciencia de él deben digerir la realidad en la que viven (Azpiazu Carballo, 2017). No solo se trata de una revisión en el presente, sino también de una revisión hacia el pasado. Entonces, aquellas personas, sobre todo las consideradas por 


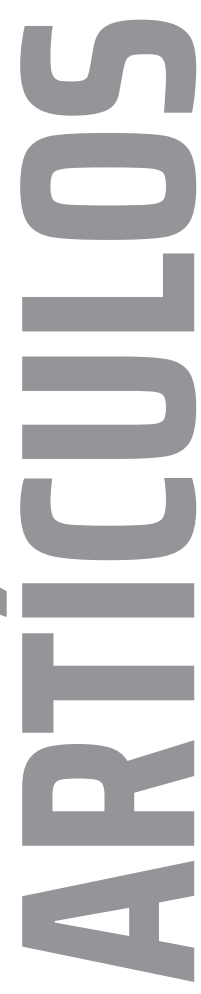

la sociedad heteropatriarcal como mujeres, deben, antes de empatizar con la teoría feminista, hacerse cargo de su estado de realidad, y cuando este se vuelve, retomando de nuevo a Rancière (2010), demasiado intolerante es donde este discurso es deslegitimado.

Podría entonces considerarse que la noción de gusto social por determinadas manifestaciones estéticas, legitimadas por el campo de poder, solo termina siendo un discurso deslegitimador de las luchas sociales. Si pensamos en el caso de las luchas sociales feministas tal deslegitimación se da, por un lado, porque son las mujeres y la comunidad LGTBQIA+ las que la llevan a cabo; $y$, por el otro, porque agencia y devela la realidad en la que vive gran parte de la población: un sistema de relaciones de poder donde el patriarcado moldea todos los espacios, tanto públicos como privados. Es esta dialéctica entre lo visible y lo invisible en las estrategias de representación de las artistas (Grüner, 2004) lo que permite cuestionar si es acaso este gusto social hegemónico una zona de confort para los sujetos; o si es simplemente una estrategia de omisión para esconder el miedo que se genera luego de la toma de conciencia del sistema patriarcal en el que se vive y se es cómplice.

\section{REFERENCIAS}

Azpiazu Carballo, J. (2017). Masculinidades y feminismos. Barcelona, España: Virus.

Bourdieu, P. (2010). El sentido social del gusto, elementos para una sociología de la cultura. Ciudad Autónoma de Buenos Aires, Argentina: Siglo Veintiuno.

Butler, J. (2002). Cuerpos que importan. Sobre los límites materiales y discursivos del sexo. Ciudad Autónoma de Buenos Aires, Argentina: Paidós.

Castro Sánchez, A. (2018). El lugar del arte en las acciones políticas feministas. Configuraciones, (22), 11-30. doi: 10.4000/configuracoes.6268

Calabrese, O. (1999). La era Neobarroca. Madrid, España: Cátedra.

Diéguez, I. (2014). Escenarios Liminales. Teatralidades, performatividades, políticas. Ciudad de México, México: Toma, Ediciones y Producciones Escénicas y Cinematográficas, A. C.

Foucault, M. (1999). Las mallas del poder. En Estética, ética y hermenéutica (pp. 235254). Barcelona, España: Paidós Ibérica.

Fuentes Feo, J. (2010). Prólogo. En M. Bellisco y M. Cifuentes (Comps.), Repensar la Dramaturgia. Errancia y transformación (pp. 5-16). Murcia, España: Centro Párraga/ Cendeac.

Grüner, E. (2004). El conflicto de la(s) identidad(es) y el debate de la representación. La relación entre la historia del arte y la crisis de lo político en una teoría crítica de la cultura. La Puerta, (1), 58-68. Recuperado de http://sedici.unlp.edu.ar/handle/10915/19994

Longoni, A. (2010). Artey Política. Políticas visuales del movimiento de derechos humanos desde la última dictadura: fotos, siluetas y escraches. Aletheia, 1(1). Recuperado de http://www.memoria.fahce.unlp.edu.ar/art_revistas/pr.4278/pr.4278.pdf 

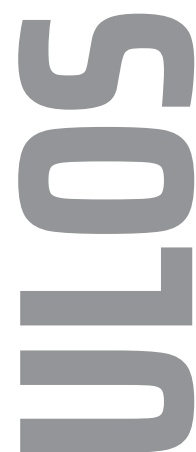

Rancière, J. (2010). El espectador emancipado. Ciudad Autónoma de Buenos Aires, Argentina: Manantial.

Taylor, D. (2011). Performance teoría y práctica. En D. Taylor y M. Fuentes (Comps.), Estudios avanzados de Performance (pp. 7-32). Ciudad de México, México: Fondo de Cultura Económica.

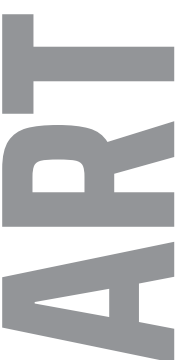

